\title{
Acumulación por despojo en los territorios agrarios chilenos
}

\author{
Patricia Castañeda Meneses ${ }^{1}$ \\ https://orcid.org/0000-0002-4676-5872
}

\author{
Ana María Salamé Coulon² \\ https://orcid.org/0000-0001-6650-7507
}

${ }^{1}$ Universidad de Valparaíso, Facultad de Ciencias Sociales, Escuela de Trabajo Social, VA, Chile

${ }^{2}$ Universidad de La Frontera, Facultad de Educación, Ciencias Sociales y Humanidades, Departamento de Trabajo Social, AR, Chile

\begin{abstract}
Acumulación por despojo en los territorios agrarios chilenos
Resumen: El artículo tiene por objetivo caracterizar los procesos de acumulación por despojo que han afectado el agro chileno tomando como referencias centrales los procesos de Reforma Agraria y Contrarreforma Agraria. Metodológicamente, se realizó investigación documental con enfoque cualitativo de textos académicos, legislación e informes técnicos de organismos gubernamentales y privados. Los resultados identifican las bases del despojo en violaciones a los Derechos Humanos y en la pérdida del rol protector del Estado en beneficio del sector privado; y analizan los efectos económicos, sociales, culturales y ambientales generados en el largo plazo. Se concluye que el agro chileno muestra evidencias de acumulación capitalista basada en procesos de despojo de sus recursos naturales, cuyos resultados son la liberalización del mercado de tierras agrícolas, el acceso expedito del capital privado a territorios rurales con producción agropecuaria tradicional y la creciente concentración de la propiedad en torno a circuitos agroindustriales y forestales.
\end{abstract}

Palabras claves: Acumulación por despojo. Territorios agrarios chilenos. Reforma Agraria. Contrarreforma Agraria.

\section{Acumulação por despojo em territórios agrários chilenos}

Resumo: Este artigo tem como objetivo caracterizar os processos de acumulação por despojo que têm afetado o agro chileno tendo como referências centrais os processos de Reforma Agrária e Contrarreforma Agrária. Metodologicamente, a pesquisa documental foi realizada com abordagem qualitativa de textos acadêmicos, legislação e relatórios técnicos por órgãos governamentais e privados. Os resultados identificam a base do desapropriamento nas violações dos Direitos Humanos e na perda do papel protetor do Estado em benefício do setor privado; e analisam os efeitos econômicos, sociais, culturais e ambientais gerados a longo prazo. Conclui-se que o agro chileno apresenta evidências de acumulação capitalista a partir de processos por despojo de seus recursos naturais, cujos resultados são a liberalização do mercado agrícola, o acesso acelerado do capital privado aos territórios rurais com produção agrícola tradicional e a crescente concentração de propriedade em torno dos circuitos agroindustriais e florestais.

Palavras-chave: Acumulação por despojo. Territórios agrários chilenos. Reforma Agrária. Contrarreforma Agrária.

\section{Accumulation by plunder in chilean agrarian territories}

Abstract: The objective of this article is to characterize the processes of accumulation by plunder that have affected Chilean agriculture, taking as central references the processes of Agrarian Reform and Agrarian Counter-Reform. Methodologically, documentary research was carried out with a qualitative approach on academic texts, legislation and technical reports from governmental and private aggencies. The results identify the bases of plunder in Human Rights violations and in the loss of the protective role of the State to the benefit of the private sector; and analyze the economic, social, cultural and environmental

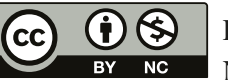

Este es un artículo publicado en acceso (Open Access) abierto bajo la licencia Creative Commons Attribution Non-Commercial, que permite su uso, distribución y reproducción en cualquier medio, sin restricciones siempre que sin fines comerciales y que el trabajo original sea debidamente citado. 
effects generated in the long deadline. It is concluded that Chilean agriculture shows evidence of capitalist accumulation based on processes of plunder of its natural resources, whose results are the liberalization of the agricultural land market, the rapid access of private capital to rural territories with traditional agricultural production and the growing concentration of ownership around agroindustrial and forestry circuits

Key words. Accumulation by plunder. Chilean agrarian territories. Agrarian Reform. Counter-Reform Agrarian.

Recebido em 24.02.2021. Aprovado em 15.05.2021. Revisado em 07.07.2021.

\section{Introducción}

Los marcos críticos de análisis de los modelos de desarrollo basados en los recursos naturales implementados en América Latina, proponen el concepto de acumulación por despojo de los autores Gilly y Roux (2009) como significativo aporte para la comprensión de las actuales formas de acumulación que se sustentan en los territorios agrarios. Para dichos autores, la expansión histórica de la relación del capital se sostiene en dos procesos entrelazados que forman parte de las dinámicas propias del capital. Por una parte los procesos de explotación, entendidos como apropiación del producto excedente en forma de plusvalor y; por otra, los procesos de despojo, expresados en formas de apropiación violenta o encubierta bajo formatos legales de los bienes naturales, comunitarios o públicos. Para Galafassi y Composto (2013) los procesos de despojo sobre los territorios agrarios de América Latina han convertido a la naturaleza en un recurso al servicio de la acumulación del capital, siendo concebidos como espacios privilegiados para la obtención de materias primas baratas. En este marco, Gilly (2014) plantea que el concepto de despojo es equivalente a la privatización de los bienes comunes, desde una concepción coextensa de los recursos naturales y del patrimonio inmaterial que definen una comunidad. En base a estos referentes, el despojo puede ser definido como "el proceso mediante el cual, a partir del ejercicio de la violencia o la coacción, se priva de manera permanente a individuos y comunidades de derechos adquiridos o reconocidos en su condición humana, con relación a predios, propiedades y derechos sociales, económicos y culturales" (CNRR/IEPRI, 2009, p. 30).

Los procesos de despojo latinoamericanos reconocen sus principales hitos históricos en la conquista y colonización europeas sucedidas entre los siglos XV y XVIII; junto con la implementación de los modelos de desarrollo basados en los recursos naturales de fines del siglo XIX y principios del siglo XX. Lo anterior define el desarrollo de la región desde la ecuación capital/recursos naturales, asumiendo un papel de proveedor de materias primas hacia el resto del mundo, principalmente de carácter agrario y minero. Esta situación sigue presente en el actual modelo basado en la privatización de los recursos naturales e implementado en contextos de globalización económica y tecnológica, cuya dinámica concibe a la naturaleza en clave mercantil a través de formas de acumulación que maximizan ganancias aún en épocas de crisis (Galafassi, 2016; Vilchis, Zizumbo, Monterroso, Arriaga y Palafox, 2016). Complementariamente, Rodríguez (2017) propone la categoría de despojo para la acumulación, entendida como una tendencia impulsada por los grupos económicos para apropiarse de bienes naturales y comunitarios como agua, bosques, suelos, minerales, fuentes de energía, y de bienes públicos a través de la privatización de servicios e infraestructura de salud, educación, carreteras, agua potable y telefonía. Con ello, las empresas y corporaciones obtienen altas rentas a partir de ganancias extraordinarias generadas cuando dichos bienes son incorporados y valorizados como mercancías en los mercados de productos y en el sistema financiero nacional e internacional.

Las relaciones presentes en los procesos de despojo permiten a los capitales mantener márgenes de ganancia, aún en tiempos de crisis o escasez; y ejercer presión sobre los recursos naturales, llegando a separar forzosamente a la población rural e indígena de sus medios de sustento y formas de vida tradicionales Con ello, imponen formas de ocupación y producción que provocan destrucción y depredación sobre los territorios rurales que ocupan, reorganizando unilateralmente los espacios conforme sus objetivos e intereses. El Estado, en alianza con los grupos de poder político y económico, facilita los procesos a través de cuerpos legales y normativas oficiales que permiten privatizar y mercantilizar los bienes naturales en beneficio del sector privado agroindustrial y financiero, limitando su rol público a la acción redistributiva de los flujos de riqueza variables que puedan ser capturados a través de la carga impositiva (Vilchis, Zizumbo, Monterroso, Arriaga y Palafox, 2016). 
En este marco, el objetivo del artículo es caracterizar los procesos de acumulación por despojo que han afectado el agro chileno y sus efectos asociados, tomando como punto de referencia central el proceso expropiatorio de la Reforma Agraria sucedido en Chile a contar del año 1962 y detenido abruptamente a contar del Golpe de Estado de Septiembre de 1973. Metodológicamente, corresponde a una investigación documental con enfoque cualitativo, en que se realizó revisión bibliográfica de los procesos de Reforma Agraria, Contrarreforma Agraria e implementación del modelo de libre mercado en el agro chileno; en legislación agraria, textos académicos e informes técnicos de organismos gubernamentales y privados vinculados con el agro, los que respaldan el proceso de análisis realizado en torno al concepto de acumulación por despojo propuesto por los autores Gilly y Roux (2009).

\section{Reforma Agraria chilena. La tierra para el que la trabaja}

La Reforma Agraria chilena estuvo orientada principalmente a modificar la histórica estructura de propiedad rural heredada desde la Conquista y expresada a través del complejo latifundio/minifundio, sistema hacendal fuertemente concentrado que operaba como la base económica del poder político tradicional (Gómez, 1988). La organización productiva se apoyaba en el inquilinaje, institución colonial basada en un acuerdo de palabra entre el propietario del predio y los campesinos sin tierra que vivían en su interior, estableciendo un acotado intercambio de derechos y obligaciones entre ambos, en precarias condiciones materiales de vida y trabajo (Oxman, 1983). El proceso reformista fue impulsado a nivel latinoamericano por la Alianza para el Progreso y secundado a nivel nacional por grupos políticos, sociales y religiosos progresistas, cuyos auspicios permitieron la dictación de la Ley de Reforma Agraria $\mathrm{N}^{\circ} 15.020$ en el año 1962, a pesar de la fuerte resistencia de sectores conservadores (República de Chile, 1962). A esa fecha, el total de tierras agrícolas alcanzaba a 20 millones 400 mil hectáreas. De ellas, un $4 \%$ del total de las explotaciones concentraban más del $80 \%$ del suelo productivo nacional y 730 explotaciones agropecuarias controlaban más de 10 millones de hectáreas, equivalente al $50 \%$ de las tierras agrícolas del país. Como contraparte, los pequeños propietarios poseían el 1,4\% del recurso (Alaluf, Robles y López, 1969). La aplicación de este primer cuerpo legal fue acotada, por presentar dificultades operativas en su aplicación, por lo que fue conocida como la Reforma del Macetero. Durante su vigencia permitió apenas la expropiación total de 17 grandes propiedades que representaban 142 mil hectáreas de toda la tierra agrícola nacional (Ortega, 1987). Por lo anterior, se tramitó la nueva Ley $\mathrm{N}^{\circ}$ 16.640 del año 1967 que mejoró el proceso, definiendo derechos campesinos de acceso a la tierra, asistencia técnica, crédito agrícola preferente, comercialización, sindicalización y cooperativismo; e impulsando los derechos sociales de salud, vivienda y educación desde políticas públicas sectoriales que prestaron especial atención al sector rural (Castañeda Meneses, 2018; República de Chile, 1967).

A partir de estas nuevas normativas, la Reforma Agraria se intensificó a través de los sucesivos períodos de los gobiernos democratacristiano de Eduardo Frei Montalva (1964-1970) y de la amplia coalición de izquierda que respaldó a Salvador Allende Gossens (1970-1973), permitiendo contar a septiembre de 1973 con un total de 5.500 predios expropiados localizados principalmente en la zona centro sur de Chile, los que representaban alrededor de 9.600 .000 hectáreas reformadas, equivalentes al 50\% del total de la tierra agrícola nacional (Bengoa, 1984). La permanencia de la tuición estatal sobre gran parte de la tierra expropiada obedecía a la necesidad de entregar asistencia técnica estatal a los procesos de producción y de comercialización de las familias campesinas, las que se encontraban afectadas por analfabetismo y bajos niveles de escolaridad, por lo que requerían acompañamiento gubernamental hasta que pudiesen hacerse cargo del proceso en forma independiente (CORA, 1970). Sin embargo, el proceso reformista enfrentó un traumático cambio a partir del 11 de septiembre de 1973, fecha del Golpe de Estado cívico militar que derrocó al gobierno constitucional. Las nuevas autoridades de facto iniciaron en 1974 un proceso de liquidación de la tierra expropiada, orientado a la instalación de un modelo económico neoliberal basado en las ventajas comparativas aportadas por los recursos naturales. Para llevar a cabo esta aspiración, se reorganizó el funcionamiento de la economía nacional aportando facilidades al sector privado para el desarrollo de sus iniciativas e inversiones; y se redefinió el tradicional rol protector del Estado por un rol público subsidiario. 


\section{Las bases del despojo: la Dictadura cívico militar y la Contrarreforma Agraria}

Los procesos de liquidación de la Reforma Agraria, también conocidos como Contrarreforma Agraria (Bengoa, 1984) se caracterizaron por entregar progresivamente los recursos agrarios al control privado, a través de una alianza entre las autoridades militares con los grupos políticos y económicos con intereses en el sector agrario. Estos procesos sentaron las bases del despojo, a través de violaciones a los Derechos Humanos y la celebración de actos jurídicos y administrativos que arrebataron, enajenaron o transfirieron derechos campesinos a terceros. Las bases del proceso de despojo son los siguientes:

a) Atentados contra la vida y la integridad personal. Según la información documentada por el Informe de la Comisión Nacional de Verdad y Reconciliación (1996) sobre violaciones a los Derechos Humanos con consecuencia de muerte en el período Septiembre de 1973 a Octubre de 1975, posterior al Golpe de Estado y en el contexto del clima de terror y represión política que se vivía en el país, suceden un total de 337 acciones de violaciones a los Derechos Humanos en el agro reformado, relacionados con la vida e integridad personal que corresponden a un $11.10 \%$ del total nacional acreditado; de las cuales 166 corresponden a ejecutados políticos, 165 detenidos desaparecidos y 6 fallecimientos por consecuencia de torturas y malos tratos. Las víctimas incluyen campesinos, dirigentes rurales, profesionales y funcionarios de reparticiones públicas a cargo de la Reforma Agraria, a quienes se les impuso la fuerza represiva por sobre los procedimientos jurídicos requeridos para realizar legalmente ingreso a domicilios, detención de personas, debido proceso y juicio justo. En muchas ocasiones se reporta la participación de civiles en la detención y asesinato de campesinos. Además existen abundantes evidencias de acciones de tortura, amedrentamiento y expulsión de familias desde las áreas reformadas. Las acciones de violencia tenían como objetivo atemorizar a la población rural, desarticular a las organizaciones campesinas e impedir nuevos movimientos reivindicativos en el agro.

b) Revocación de Derechos campesinos garantizados por Ley. Una vez efectuado el Golpe de Estado, las garantías estatales respecto a los derechos campesinos declaradas en los cuerpos legales reformistas fueron completamente anulados, dejando al sector reformado sin ningún tipo de apoyo para enfrentar sus procesos productivos y sin facilidades para cancelar sus compromisos por pago y tributación de la tierra asignada (GIA, 1979; Bengoa, 1984).

c) Revocaciones de predios del proceso de incorporación formal a la Reforma Agraria. Para acelerar las expropiaciones durante el proceso reformista, las organizaciones campesinas implementaron ocupaciones de hecho de los predios, las que fueron conocidas como tomas de fundo, las que posteriormente eran formalizadas por los organismos del agro que tomaban posesión de los predios, oficializando su ingreso al proceso. Las autoridades dictatoriales definieron esta situación como irregular, revocando entre 1974 y 1975 las expropiaciones de 1.736 fundos y restituyendo parcialmente 2.176 propiedades a sus antiguos dueños, sumando un total de 3.182.255 hectáreas revocadas, equivalente al $34 \%$ de las tierras que se encontraban en poder del Estado a Septiembre de 1973 (Bengoa, 1984; Ortega, 1987).

d) Marginación campesina del proceso de adjudicación de tierras. Los requisitos legales para la asignación de tierras consideraba la condición de ser jefe de hogar campesino a cargo de un grupo familiar. Posterior al Golpe de Estado se dictaron los Decretos Ley 208 del año 1974 y 1.600 del año 1976, que modificaron los criterios de selección y otorgaron mayores puntajes por escolaridad formal o años de servicio, permitiendo la participación de profesionales y funcionarios públicos en las asignaciones, los que desplazaron a los campesinos en las listas de selección (República de Chile, 1976; 1974). También se aumentó la ponderación de la opinión patronal respecto del comportamiento laboral campesino y se sumaron como prohibiciones el cumplimiento de condenas penales y la participación en ocupaciones irregulares de predios. Estas nuevas normas se aplicaron en forma amplia, afectando el derecho de propiedad de unas 70 mil familias campesinas y marginando a dirigentes campesinos, especialmente si contaban con sospecha o evidencia de militancia partidista de centro izquierda (Gómez, Arteaga y Cruz, 1979). Estas medidas forzaron el abandono de las tierras reformadas por parte de las familias no asignadas, las que engrosaron la población en situación de pobreza en las zonas urbanas o crearon villorrios rurales en sitios eriazos o sin dueños, los que se transformaron posteriormente en puntos clave de contratación de la mano de obra temporal para las faenas agrarias (GIA, 1979). 
e) Pérdida por venta forzada de la tierra reformada asignada a familias campesinas. El $41 \%$ de tierras expropiadas fueron asignadas inicialmente a un total de 54.564 familias campesinas a través de proyectos de parcelación de unidades agrícolas familiares y cooperativas. Sin embargo, estas asignaciones se incorporaron rápidamente al creciente mercado de tierras agrícolas en condiciones devaluadas, ante la total imposibilidad de los propietarios iniciales de hacer frente a sus gastos por carecer de apoyo estatal para asumir garantías bancarias de acceso al crédito o endeudamiento. A mediados de la década de 1980, se estimaba que el $60 \%$ de los campesinos asignatarios había perdido sus parcelas por venta o remate por deudas impagas (Bengoa, 1984). El proceso seguiría profundizándose en las décadas posteriores, afectando el $10 \%$ del total de las tierras agrícolas a nivel nacional (Echeñique y Rolando, 1991).

f) Entrega de tierras reformadas y recursos públicos agrarios al sector privado. El proceso de liquidación por parte del Estado se tradujo en licitaciones entregadas a privados por medio de subasta pública o venta directa, destinando para este fin un tercio de la tierra expropiada. A lo anterior, se sumó la venta de infraestructura agrícola, maquinarias, complejos agroindustriales, predios agrícolas, bosques y terrenos forestales, a los que accedieron conglomerados financieros en condiciones altamente ventajosas. Este patrimonio había sido resultado de políticas públicas iniciadas en la década de 1940 y representaban cuantiosas inversiones del Estado destinadas a mejorar las condiciones de productividad del agro nacional y financiar proyectos en ciencia y tecnología (Bulnes, Celedón, Coll, Fuenzalida y González, 2004). A lo largo de las décadas se han continuado traspasando cuantiosos recursos públicos al sector privado en forma de subsidios, subvenciones, créditos preferentes, instrumentos de fomento productivo y fondos para investigación aplicada, innovación tecnológica y transferencia de conocimientos (Wernli, 1993; INFOR, 1993).

g) Pérdida de la calidad de tierra indígena en las comunidades mapuche. La dictación del DL $\mathrm{N}^{\circ} 2.568$ de 1978 declaró como objetivo el saneamiento de la propiedad de los títulos de dominio de las comunidades mapuche sobre sus tierras comunitárias (República de Chile, 1978). Estas tierras fueron asignadas durante los procesos de radicación forzosa realizados durante la ocupación militar de la Araucanía realizada a fines del siglo XIX, que buscaba ampliar la frontera agrícola e impulsar la colonización nacional y extranjera en la zona sur de Chile. En términos prácticos, se liquidó tierra comunitaria mapuche y se asignó propiedad individual sobre la misma a través de la línea de derechos hereditarios. Asimismo, se definieron procedimientos de compra venta y arrendamientos que facilitaron la incorporación de la tierra indígena al mercado de tierras preferentemente con fines agrícolas, forestales y turísticos (Muñoz, 1999).

h) Entrega por parte del Estado de los derechos de agua a particulares a título gratuito y a perpetuidad. A través de la dictación del Decreto Ley no 2.603 de Abril de 1979 y el Decreto con Fuerza de Ley 1.122 de 1981 que fija texto del Código de Aguas, el recurso hídrico dejó de ser considerado un bien nacional de uso público y los derechos de aprovechamiento fueron definidos como un derecho real de dominio, permitiendo a los privados acceder a la propiedad, el manejo y el desarrollo del recurso con la sola manifestación de la voluntad, cursando la respectiva inscripción en el Conservador de Bienes Raíces de cada comuna (República de Chile, 1981; 1979). Los derechos de aprovechamiento fueron otorgados gratuitamente por el Estado a los particulares que lo solicitaron, facilitando el acceso al recurso a grupos económicos y grandes propietarios agrarios quienes formaban parte de los círculos de confianza de las autoridades militares de la época. Actualmente, el $90 \%$ de los derechos de agua están en propiedad de empresas mineras y agroexportadoras (Mundaca, 2012).

\section{Los efectos del despojo en el largo plazo. Acumulación capitalista en el agro}

Como resultado de las acciones de despojo, se configuró una amplia base de recursos naturales en propiedad de privados que ha permitido la acumulación de capitales y ha generado efectos económicos, sociales, culturales y ambientales en el largo plazo.

a) Efectos económicos. Existe una alta concentración de la propiedad agraria con especialización productiva de los territorios a través de circuitos agroindustriales y forestales, la que busca garantizar bajos costos de producción y asegurar rentabilidad y eficiencia en sus operaciones. Actualmente, los grupos económicos agrarios son dueños de un estimado del 70\% del recurso suelo. Particularmente, las empresas forestales controlan la mayor parte del territorio con conglomerados que poseen hasta un 
millón de hectáreas como patrimonio. Como contraparte, el $75 \%$ de los pequeños propietarios rurales maneja menos del $4 \%$ de la tierra en predios de menos de 5 hectáreas en promedio. Estos antecedentes sitúan a Chile como el segundo país con la mayor concentración de la propiedad agraria a nivel de América Latina (Oxfam, 2016). Respecto a la especialización productiva del territorio, a fines de la década de 1970, el país contaba con 16 plantas de procesamiento agrícola, implementadas con el apoyo de estudios técnicos y proyecciones económicas realizadas por organismos públicos. Sobre la base de dicho conocimiento generado por el Estado, junto con el acceso preferente a la tierra cultivable, el apoyo de instrumentos públicos de fomento y la inversión de capitales propios y extranjeros; la expansión de las cadenas hortofrutícolas alcanza actualmente a 219 agroempresas que abarcan los subsectores de conservas, congelados, deshidratados, jugos y aceites, exportando el $80 \%$ de su producción anual y situando a Chile como primer exportador frutícola del hemisferio sur. Las cadenas agroindustriales poseen sus propios predios para la generación de su materia prima y constituyen importantes poderes compradores en sus zonas de influencia para la adquisición de remesas complementarias. La mayor demanda por mano de obra para faenas de cosecha sucede entre los meses de diciembre a abril, siendo reclutadas preferentemente mujeres por sus habilidades de recolección, las que representan en promedio el 67\% del recurso humano contratado (ODEPA, 2012). Por su parte, el sector forestal ha apoyado su dinámica expansiva en subsidios estatales entregados principalmente por el Decreto Ley $\mathrm{N}^{\circ} 701$ de 1974, que aportó recursos públicos para forestación y reforestación con especies exógenas de rápido crecimiento priorizadas por sobre las especies nativas. Las mayores inversiones están en la industria forestal, a través de plantas de procesamiento de celulosa con tecnología de última generación, junto con infraestructura caminera, ferroviaria y portuaria complementaria, las que reorganizan los territorios para facilitar la exportación de su producción (República de Chile, 1974). Asimismo, se constituyen como poderes compradores de tierras y bosques para garantizar la estabilidad de la materia prima en el largo plazo. El sector forestal ha creado un mercado contratista complementario en torno al manejo y explotación de las plantaciones; junto con servicios de transporte, insumos y comercialización del recurso, en donde se integra mano de obra estacional preferentemente masculina y con baja calificación (ODEPA, 2017; Meneses y Coulon, 1995).

b) Efectos sociales. Se expresan principalmente en la población rural, la que ha sido desplazada de los territorios que ocupaba tradicionalmente debiendo reubicarse forzosamente en villorrios rurales que concentran población proveniente de zonas de despeje, o siendo impulsada a migrar hacia zonas urbanas. Estos efectos pueden observarse en los datos intercensales 1970-2017, los que muestran importantes cambios en la distribución poblacional. Así entonces, a inicios de la década de 1970 la distribución de la población chilena era de un $75.13 \%$ en zonas urbanas y un $24.87 \%$ en zonas rurales, lo que se ha modificado progresivamente con el paso de las décadas, informando en la última medición censal realizada el año 2017 una concentración urbana de $87.8 \%$ y un 12,2\% de población rural. Las zonas rurales presentan un progresivo despoblamiento y no logran retener a su población joven, generando un fenómeno de envejecimiento poblacional localizado. A nivel nacional, la población mayor de 60 años alcanza a $11,4 \%$, estimándose un $17,3 \%$ en el año 2020 , existiendo proporcionalmente $2,4 \%$ más de personas mayores en los sectores rurales que en los urbanos. Como contraparte, la población joven entre 15 y 29 años se localiza en un $88 \%$ en zonas urbanas y $12 \%$ en zonas rurales, correspondiendo al $20 \%$ de la población rural total (INE, 1970; INE, 2017). La migración juvenil rural obedece por una parte, a la búsqueda de oportunidades educacionales y laborales más favorables en la ciudad; y por otra, a la imposibilidad de acceder a recursos productivos básicos como tierra, agua, créditos agrícolas y prácticas agrícolas mejoradas, debiendo enfrentarse a opciones laborales precarias en trabajos temporales de baja calificación en la agroindustria y en el sector forestal.

c) Efectos culturales. Los principales efectos se manifiestan en la cultura campesina y en el grupo étnico mapuche. En relación al primer efecto, la pérdida de la base de sustentación económica tradicional de la agricultura familiar, tiene como correlato la pérdida de sus prácticas culturales y de su patrimonio inmaterial fuertemente arraigado en los territorios. En consecuencia, el despoblamiento rural y el envejecimiento de la población campesina amenazan con una pérdida irreparable de la identidad cultural en un futuro próximo, que afectan su sobrevivencia y proyecciones futuras. Un segundo efecto de carácter localizado corresponde al denominado Conflicto Estado/Pueblo Mapuche, que expresa los problemas derivados 
del avance del sector forestal en la zona centro sur del país, que ha desplazado progresivamente los soportes de la agricultura familiar campesina del pueblo mapuche, afectando su reproducción cultural material e inmaterial. La actividad forestal ha dañado gravemente la biodiversidad de su territorio, empobreciendo la base productiva agrícola y recolectora tradicional y generando efectos ambientales negativos sobre los recursos naturales locales. Las históricas demandas de reivindicación mapuche hacia el Estado por recuperar sus territorios ancestrales, enfrentan las dificultades estructurales derivadas de la alta concentración de la propiedad rural que alcanza la actividad forestal y las dinámicas acumulativas de sus actividades, que se contraponen las valoraciones culturales mapuche en torno a relaciones armónicas y respetuosas con la naturaleza. La expansión forestal ha profundizado las manifestaciones de un conflicto en que se contraponen intereses económicos, valoraciones de los recursos naturales y legítimas reivindicaciones históricas que demandan acciones de reparación y restitución en medio de un territorio rural en abierta disputa (Figueroa, 2018; Meneses y Coulon,1995).

d) Efectos ambientales. Los procesos de acumulación capitalista han generado enormes presiones sobre los recursos naturales, impulsando transformaciones estructurales que afectan el medio ambiente rural. Sus principales expresiones corresponden a la introducción indiscriminada de extensos monocultivos que disminuyen drásticamente la biodiversidad en los ecosistemas, incorporación de cultivos exógenos o transgénicos, pérdida de flora y fauna nativa, vulnerabilidad frente amenazas de plagas y megaincendios forestales, erosión por sobreexplotación, escasez hídrica, acidificación de los suelos y uso intensivo de agroquímicos contaminantes de aire, suelo y agua. Los procesos industriales realizan emisiones tóxicas con altos volúmenes de residuos y con enorme consumo de recursos energéticos. Estas manifestaciones se definen como "zonas de sacrificio", concepto asociado a la sobreexplotación de los recursos naturales y su posterior abandono una vez finalizados los ciclos productivos intensivos, careciendo de medidas de compensación o recuperación ambiental que permitan proteger a los territorios y a la población rural de los efectos negativos derivados de las actividades realizadas. La respuesta social a la profundización y expansión de los proyectos de mercantilización de bienes naturales se expresa en un creciente ascenso de la conflictividad ambiental en los territorios rurales. Agrava esta realidad, el cambio climático global, expresado en prolongadas sequías por disminución del régimen histórico de lluvias y deshielo de glaciares en la cordillera de Los Andes por aumento de las temperaturas promedio del valle central. (Bergamini, Irarrázabal, Monckeberg y Pérez, 2017).

\section{Consideraciones finales}

A la luz de los análisis realizados precedentemente, es posible concluir que el agro chileno muestra amplias evidencias de acumulación capitalista basada en procesos de despojo de sus recursos naturales, originado desde la convergencia del proyecto represivo de la dictadura cívico militar y el proyecto económico agrario de grupos de interés conservadores, quienes formaron una estrategia única orientada a expulsar a las familias campesinas de las tierras reformadas por medio de acciones de terrorismo de Estado, vulneración de derechos campesinos a través de normativas que formalizaron el proceso de despojo y priorizaron los intereses de grupos económicos vinculados al agro por sobre los intereses campesinos. Todo ello trajo como resultado la liberalización del mercado de tierras, el acceso expedito del capital privado a territorios rurales con producción agropecuaria tradicional y la concentración de la propiedad en circuitos agroindustriales y forestales. Caracterizar el proceso de despojo del agro chileno en el ciclo de largo plazo que representan las últimas cinco décadas, refleja una dinámica de progresivo retroceso de la propiedad tradicional agraria y de pérdida de recursos del Estado por procesos privatizadores, la que ha empujado pendularmente desde la concentración histórica de tierras en manos de la propiedad hacendal latifundista que ejercía poder político, hacia una concentración de tierras en manos de conglomerados nacionales y transnacionales que ejercen poder económico, los que han insertado las ganancias obtenidas en el circuito internacional de acumulación capitalista, amplificando los efectos del despojo a nivel global. En la interfaz de este movimiento pendular se encuentran las familias asignatarias de la Reforma Agraria, quienes fueron vulneradas en sus derechos campesinos y abandonadas por el Estado, quien no cumplió su rol garante del proyecto de desarrollo agrario con orientación social, conforme había sido acordado por el país en el marco del proceso reformista. Como 
consecuencia, la población rural se redefinió forzosamente desde inquilina o campesina tradicional, a fuerza trabajadora de temporada en circuitos agroindustriales o forestales en condiciones de precariedad laboral, situación que impulsa la migración hacia centros urbanos y el abandono de prácticas ancestrales campesinas.

En este entramado también se reconocen las características del despojo para la acumulación capitalista, en donde las ganancias de los procesos productivos agrarios pertenecen centralmente a los grupos económicos propietarios de los recursos naturales. Las pérdidas que representan los efectos económicos, sociales, culturales y ambientales del despojo se han conjugado con las derivadas de ciclos económicos adversos a lo largo de las décadas, recayendo directamente sus costos sobre los territorios y las poblaciones rurales que sostienen un modelo de desarrollo inequitativo, inconsulto e impuesto por la fuerza. Con ello, además se evidencia que los gobiernos del período postdictatorial han administrado el modelo, sin aportar cambios estructurales que permitan modificar el funcionamiento general del sistema en beneficio de las mayorías. En este marco, el Estado sigue limitado a su rol subsidiario, recibiendo en sus arcas los ingresos derivados de las cargas impositivas pactadas con el sector privado. Todo intento de modificar estos mecanismos se enfrentan con la permanente amenaza de pérdida de confianza de los inversionistas y con la difícil anuencia de la fuerte contraparte agroempresarial involucrada, siempre renuente a aceptar nuevas condiciones de funcionamiento. Finalmente, a modo de corolario, puede plantearse dos paradojas centrales. Por una parte, en la agroindustria la dulzura de la fruta chilena se apoya en la amargura de los territorios que la sostienen; y en el sector forestal los árboles (de las plantaciones) no dejan ver el bosque (nativo), arrasado desde sus territorios ancestrales. Ambas paradojas declaradas como dolorosas evidencias de una historia agraria de despojo que aún no termina de escribirse en el agro chileno.

\section{Referencias}

ALALUF, D, ROBLES, E \& LÓPEZ, A. (1969). Cambios ocurridos en la agricultura chilena en el período comprendido entre los censos agropecuarios 1955 y 1965. Santiago: ICIRA.

BENGOA, J. (1984). El campesinado chileno después de la Reforma Agraria. Santiago de Chile: Ediciones Sur.

BERGAMINI, K, IRARRÁZABAL, R, MONCKEBERG, J \& PÉREZ, C. (2017). Principales problemas ambientales en Chile. Desafíos y Propuestas. Santiago de Chile: Centro de Políticas Públicas, Pontifica Universidad Católica de Chile.

BULNES, J, CELEDÓN, R, COLL, M., FUENZALIDA, S. \& GONZÁLEZ, L. (2000). Identificación y diagnóstico jurídico de casos ilustrativos por regiones de tierras afectadas por la reforma agraria que presentan irregularidades en su adjudicación o tenencia actual, y alternativas de regularización, reparación o indemnización posible a sus beneficiarios originales, por vías administrativas, judiciales o legislativas. Santiago de Chile: Ministerio de Agricultura/Universidad ARCIS.

CASTAÑEDA MENESES, P. (2018). 50 años de la Reforma Agraria chilena. De la protección a la vulneración de los derechos campesinos. Revista Latinoamericana De Derechos Humanos, 28(2), 193-212.

CNRR/IEPRI. (2009). El despojo de tierras y territorios. Aproximación conceptual. Coedición: Área de Memoria Histórica - Comisión Nacional de Reparación y Reconciliación (CNRR)/Instituto de Estudios Políticos y Relaciones Internacionales (IEPRI) - Universidad Nacional de Colombia. Bogotá. CNRR/IEPRI. Recuperado de: http://www.centrodememoriahistorica.gov.co/descargas/informes2010/ tierra_conflicto/despojo_tierras_baja.pdf

CORA. (1970). Reforma Agraria Chilena 1965-1970. Santiago de Chile: Corporación de la Reforma Agraria. Ministerio de Agricultura. ECHEÑIQUE, J \& ROLANDO, N. (1991). Tierras de parceleros: ¿Dónde están? Santiago de Chile: Agraria.

FIGUEROA, V. (2018). Tierras y territorios indígenas. Dimensiones complejas para las Políticas Públicas. El caso de la Política “Acuerdo Nacional por el Desarrollo y la Paz en la Araucanía- Plan Impulso Araucanía” en Chile. Serie Policy Papers. Santiago de Chile: Unidad de Políticas Públicas, Centro de Estudios Interculturales e Indígenas, Pontificia Universidad Católica de Chile.

GALAFASSI, G \& COMPOSTO, C. (2013). Acumulación por despojo y nuevos cercamientos: el caso de la minería a gran escala en la Patagonia argentina. Cuadernos del Cendes, 30(83), 75-103.

GALAFASSI, G. (2016). Entre la acumulación primitiva y la reproducción ampliada. Una reactualización del debate y su correlación con la explicación de los conflictos sociales en América Latina. Política. Revista de Ciencia Política, 54(2), 49-73.

GIA. (1979). Los parceleros de la Reforma Agraria. Santiago de Chile: Grupo de Investigaciones Agrarias, Academia de Humanismo Cristiano.

GILLY, A \& ROUX, R. (2009). Capitales, tecnologías y mundos de la vida. El despojo de los cuatro elementos. Los condicionantes de la crisis en América Latina. Inserción internacional y modalidades de acumulación. Buenos Aires: CLACSO, 2009. 
GILLY, A. (2014). El tiempo del despojo. Poder, trabajo y territorio. Debate Feminista, 50, 35-48.

GÓMEZ, S. (1988). La Agricultura chilena: las dos caras de la modernización. Santiago de Chile: Flacso Agraria.

GÓMEZ, S, ARTEAGA, J \& CRUZ, M. (1979). Reforma agraria y potenciales migrantes. Santiago de Chile: FLACSO. Documento de Trabajo $n^{\circ} 82$.

INE. (1970). Resultados oficiales censo de población y vivienda 1970. Santiago de Chile: Instituto Nacional de Estadísticas.

INE. (2017). Síntesis de resultados Censo 2017. Santiago de Chile: Instituto Nacional de Estadísticas.

INFOR. (1993). El sector forestal en Chile. Logros y desafíos. Santiago de Chile: Instituto Forestal (INFOR).

MENESES, C \& COULON, AMS. (1995). Transformaciones Agrarias y Pobreza Rural. 20 años de fomento forestal en la Araucanía. Revista de Trabajo Social, n. 66, p. 55-68. Santiago de Chile. Pontifica Universidad Católica de Chile.

MUNDACA, R. (2012). La privatización de las aguas en Chile viola los Derechos Humanos. Centro de Investigación Periodística Independiente (CIPER). Recuperado de: https://www.ciperchile.cl/2012/02/17/la-privatizacion-de-las-aguas-en-chile-viola-losderechos-humanos/

MUÑOZ, B. (1999). Derechos de propiedad y pueblos indígenas en Chile. Santiago de Chile: Unidad de Desarrollo Agrícola División de Desarrollo Productivo y Empresarial, CEPAL.

ODEPA. (2012). Actualización del catastro de la agroindustria hortofrutícola chilena. Santiago de Chile: Oficina de Estudios y Políticas Agrarias (ODEPA), Subsecretaría de Agricultura, Ministerio de Agricultura.

ODEPA. (2017). Agricultura chilena. Reflexiones y desafíos al 2030. Oficina de Estudios y Políticas Agrarias (ODEPA), Subsecretaría de Agricultura, Ministerio de Agricultura. Recuperado de: https://www.odepa.gob.cl/wp-content/uploads/2018/01/ReflexDesaf_2030-1.pdf ORTEGA, E. (1987). Transformaciones agrarias y campesinado. De la participación a la exclusión. Santiago de Chile: Corporación de Investigaciones Económicas para Latinoamérica (CIEPLAN).

OXFAM. (2016). Desterrados: tierra, poder y desigualdad en América Latina. OXFAM América Latina.

OXMAN, V. (1983). La participación de la mujer campesina en organizaciones: los centros de madres rurales. Santiago de Chile: Grupo de Investigaciones Agrarias, Academia de Humanismo Cristiano.

REPÚBLICA DE CHILE. (1974). Decreto Ley no 208. Modifica la Ley no 16.640 de Reforma Agraria y declara inexpropiables los predios que se encuentran en la situación que indica. Ministerio de Agricultura.

REPÚBLICA DE CHILE. (1962). Ley de Reforma Agraria nº 15.020. Ministerio de Agricultura.

REPÚBLICA DE CHILE. (1967). Ley de Reforma Agraria nº 16.640. Ministerio de Agricultura.

REPÚBLICA DE CHILE. (1976). Decreto Ley nº 1.600 sobre Reforma Agraria y Establece Normas sobre enajenación de tierras asignadas. Ministerio de Agricultura.

REPÚBLICA DE CHILE. (1978). DL nº 2.568 Modifica Ley nº 17.729, sobre protección de indígenas, y radica funciones del Instituto de Desarrollo Indígena en el Instituto de Desarrollo Agropecuario. Ministerio de Agricultura.

REPÚBLICA DE CHILE. (1979). DL nº 2.603. Modifica y Complementa Acta Constitucional $\mathrm{n}^{\circ} 3$ y establece normas sobre derechos de aprovechamiento de aguas y facultades para el establecimiento del régimen general de aguas. Ministerio de Agricultura.

REPÚBLICA DE CHILE. (1981). Decreto con Fuerza de Ley nº 1.122. Fija texto del Código de Aguas. Ministerio de Justicia. Ministerio de Economía, Fomento y Reconstrucción, Ministerio de Obras Públicas. Ministerio de Agricultura.

RODRÍGUEZ, C (2017). Despojo para la acumulación. Un análisis de los procesos de acumulación y sus modelos de despojo. Bajo el Volcán, 17(26), 41-63. Recuperado de: https://www.redalyc.org/pdf/286/28655577003.pdf

VILCHIS, A, ZIZUMBO, L., MONTERROSO, N, ARRIAGA, E \& PALAFOX A. (2016) Dinámicas capitalistas para la acumulación por despojo Revista de Ciencias Sociales (Cr), 1(151), 31-41.

WERNLI, C. (1993). La investigación agropecuaria en Chile. Enfoque presente del Instituto de Investigaciones Agropecuarias. Agricultura Técnica. Instituto de Investigaciones Agropecuarias (INIA). 


\section{Patricia Castañeda Meneses}

patricia.castaneda@uv.cl

Doctora en Ciencias de la Educación, Universidad de Barcelona (UB)

Académica e Investigadora. Escuela de Trabajo Social, Universidad de Valparaíso (UV)

\section{UV}

Escuela de Trabajo Social

Avda. Colón, 2128 Valparaíso

Región de Valparaíso - Chile

CP: 2363050

\section{Ana María Salamé Coulon}

ana.salame@ufrontera.cl

Doctora en Ciencias de la Educación, Universidad de Barcelona (UB)

Académica e Investigadora, Departamento de Trabajo Social, Universidad de La Frontera (UFRO)

\section{UFRO}

Avda. Francisco Salazar, 1145- Temuco.

Región de La Araucanía

Chile CP: 4811230

\author{
Agradecimentos \\ No aplica. \\ Agência financiadora \\ No aplica. \\ Contribuições das autoras \\ $\mathrm{El}$ artículo se elaboró en forma conjunta. El aporte de las \\ autoras es equivalente.
}

\author{
Aprovação por Comitê de Ética \\ No aplica. \\ Consentimento para publicação \\ Consentimiento de las autoras para publicación. \\ Conflito de interesses \\ No hay conflicto de intereses.
}

